\title{
IMPACT OF URBANISATION ON CULTURAL IDENTITY AND TOWNSCAPE CHARACTERISTICS OF KUALA LUMPUR CHINA TOWN, MALAYSIA
}

\author{
SHAHRUL YANI SAID \& SITI NUR AISYAH AHMAD HAMZAH \\ University Teknologi Mara, Malaysia
}

\begin{abstract}
Urbanisation had led to the destruction of traditional urban areas in Kuala Lumpur, which is why the reputation of the city's historical picture is dominated by modernity. With the fast-changing growth of new developments, there is a lack of harmony between the old and the latest developments in Kuala Lumpur city area. Urbanisation had created new attractions with various forms of architectural expressions. New buildings constructed within the city's traditional areas are different and sometimes indicated as the unwelcome contiguity to the architectural heritage of the street. This study outlines the interrelationship between principles of urban design such as identity, image and sense of place and its role in representing cultural identity of a place. It aims to identify the impacts of urbanisation on the cultural identity and townscape character of a heritage area. The case study area is within the Petaling Street, a China Town area of Kuala Lumpur, a traditional urban area famous for its trading activities and Chinese-style shophouse architecture. A townscape assessment survey was carried out to assess the physical condition of the area and observations were recorded. The result indicates a need for a comprehensive conservation management where the consideration should be in sustaining the cultural identity and historic characteristics of the heritage area.

Keywords: traditional urban areas, urbanisation, pattern of spaces, image and identity.
\end{abstract}

\section{INTRODUCTION}

With the fast-changing in the growth of new developments in Kuala Lumpur, urbanisation had created new attractions with various forms of architectural expressions. Some of these expressions are considered as insensitive towards their surrounding areas. This unpleasant contiguity can take effects at the street level, which may affect the survival of the buildings along a heritage area. Most of the buildings that are considered as old buildings with heritage values and are worth preserve might lose its heritage values without official protection or any conservations efforts.

Urbanisation had led the historic urban areas in Kuala Lumpur to deteriorate; hence the identity of the historical image of the city is now being dominated by modernity [1]. As we can see within this modern era, rapid developments towards urbanisations are seen as an important factor in chasing all other countries around the world to be competent in developing a country. Many had surpassed the idea that it is important to retain the heritage values that a city had been developing over the years. This valuable value needs to be retained in order for the next generations to identify their roots and to help in not losing the identity of the origins and roots embodied within us.

It is important to move the country towards urbanisations, nonetheless, it is also important to retain the heritage values a city might have its benefits too. Heritage areas highlight a special character of the place and represent our roots and identity. Based on studies by Shamsuddin and Ujang [2], the areas of Malaysia old town have a robust sense of place as compared to the newly developed town in Malaysia. There has been no particular investigation on the traditional street, but there is a study in the old town centre.

One of the prominent traditional streets in Malaysia would be Petaling Street. It is a China Town in Kuala Lumpur and was known as where the early Chinese settlers first settle down 
in the booming of tin mining activities in the 1800s. The activities in this area still exist up until today, which shows that it has undergone a diverse phase of evolution. This unique place saw the social interaction between races since its early years. Like most of cities built and administered by the British, segregation between races took place in Kuala Lumpur. People are divided by their races and define by their role in the community. Here, the Chinese played important role in trading and economic activities, hence its locality in near the heart of the city centre.

Petaling Street is listed in Kuala Lumpur Structure Plan 2020 as on of the City Centre's most significant historic streets in the City. Besides improving the general environment of the older areas, urban renewal initiatives shall be directed towards capitalising upon the existing assets and comparative advantages of Kuala Lumpur to create new tourist facilities [3]. The plan also listed that the older urban areas such as Petaling Street shall be preserved and the infrastructure and building quality and general living and working environment upgraded. Conservation and preservation plans for heritage areas will promote a pedestrian friendly ambience and maintain the rich diversity of street pattern and building vernacular that these areas display.

This study aims to recognise the identity of a heritage area in Kuala Lumpur within the old China Town area, whether they are affected by the factor of urbanisations. There are several factors that are being measured which are the physical and environmental indicators, image and identity indicators, and physical changes along with the areas. Measuring the physical changes in the studied area is crucial to identify the impact of urbanisation activities taken place on the cultural identities of the area and its townscape characteristics.

Thus, this study is to achieve several objectives such as:

a) To study the impact of urbanisation on the physical townscape characteristic and architectural heritage of Kuala Lumpur China Town area by visual survey.

b) To identify the relation of urbanisations towards the sustainability of the identity of Kuala Lumpur China Town area.

The result may help in indicating the changes that have taken place and mark the area that needs to be improved. Moreover, the pattern of changes that had been formed over the years will be studied, which in future may help in conducting conservation works towards the buildings in the existing area

\section{URBANISATION AND THE IMAGE AND IDENTITY OF A PLACE}

Urbanisation refers to a variety of disciplines, which includes urban planning, geography, sociology, architecture, economics and public health. The pattern was closely associated with globalisation, industrialisation, and the sociological rationalisation method. Urbanisation can be defined at a given time as a specific condition (e.g. the proportion of overall population or region in towns or cities) or as an increase in that condition through time.

Urbanisation is not just a relatively new phenomenon, but an accelerated and historic transition of human social origins on a worldwide scale, substituting primarily rural culture by replacing it with predominantly urban culture. It is the transition from rural to urban society, caused by changes in cultural, economic and social activities within the society. Moreover, all nations are facing the challenges of the environment, social, transportation, economy in their respective cities in the current global atmosphere. These problems are common in developing countries because of the disparity in urban and village growth.

Within the conservation issues, the limitation exists in the conserving of the individual building only and not within the in-between spaces of heritage buildings. The image, together with the identity of the heritage street is important in creating a place rather than a new 
conserved building [4]. The two major elements of the urban space in the older towns and cities in Malaysia are the streets and the shophouses built along with it. These earlier streets were built to accommodate not only for the earliest modes of transportation but to accommodate the pedestrians to walk along with the buildings [5]. As proposed by Lynch [6], pedestrian networks create a more humanly town rather than traffic roads that are laid across town.

In Kuala Lumpur, the early building that exists in the traditional areas of the cities consists of two-storey shophouses that are typically linked together with a $5 \mathrm{ft}$ walkway. These shophouses hold retail activities and residential area to the owners of the building. The $5 \mathrm{ft}$ walkway provides protections towards rain and shades to the pedestrians that pass through the area. New buildings built within the traditional areas of the cities create different traits and this can be considered as the unpleasant contiguity towards the visual street heritage. Some buildings do not offer a $5 \mathrm{ft}$ walkway, which disconnects the continuous walkability experience together with some of the buildings that are totally different heights from the other [7]. Further intrusions could create uneasiness towards the identity of the built heritage area in a city. Nevertheless, these buildings have ages throughout time; the fabric depicts the patina of time and a physical evidence of history of the place. Throughout time, the building overcome changes and this changes continue along with urbanisation process.

\subsection{Defining character and identity}

Character is described as the value aggregate that distinguishes one person or thing from the other. Being out of character, based on the Macquarie Dictionary, describes the contradiction of what is previously known, or behaviour etc. An example from Tuan [8] best describes the place character and place attachments:

"a place that evokes affection has personality in the same sense that an old raincoat can be said to have character. The character of the raincoat is imparted by the person who wears it and grows fond of it. The raincoat is for use, and yet in time it acquires a personality, a certain wayward shape and smell that is uniquely its own”.

Character and identity can be seen as a concept. Understanding character is not straightforward and needs a practical tool for analysing and describing it. There are three perspectives on the sense of identity within the context of the architecture and urban design that are: difference/similarity, continuity/evolution, and unity/multiplicity. Identity has the highest standards of physical quality in urban areas according to Schulz in Boussaa [9].

\subsubsection{The character of a townscape}

A successful townscape can be determined from how effective a townscape can contribute, and how lively they are created. Spaces between buildings and the buildings in between themselves had strong relationships together thus are very much affected by townscape. In other words, visual visions that are experienced from the observer point of view can create impacts towards the sense of place which includes the emotions felt by the observer with how they actually felt passing through a place.

The interplay on the foundations of a townscape can be summarised by the serial visions, place, content and their functional traditions they uphold. As stated by Cullen, these values had impacts on the emotional response on the human experience as they observe the townscape. This supports the statement where the characteristics a city had may affect the activities held within an area or a place that includes when any major changes were made to the existing physical elements through an area can give impacts to the activity pattern, 
which directly affects the behaviour of the peoples that lives in it. The changes of the sociocultural activities could be seen through physical appearance of a townscape and changes of usage of the architectural heritage.

Based on studies by Ja'afar et. al., townscape had influenced the behaviour of the users together with their activity patterns hence concludes that the townscape character had affects the surrounding environments of the people within the place [10]. The characteristics are divided into two, which are the tangible and intangible aspects as they contributed to the character of a town. Tangible is the man-made or any physical features within an area while intangible aspects refer to the human behavioural and cultures created by them within a place.

As a concept, townscape can be defined as a piece from a city which had its own character attached to it that is significant towards the observer's point of view. An enhanced sense of belonging qualities of a townscape is a result of the ability of a city in having a clearer image with a strong sense of identity it projects. The cultural activity that was carried out within a place contributes to the identity and character of the place. It formed a genus locus that makes a place what it is. As for Petaling Street, Chinese trading activities and shophouses is the element that represents its identity. The highlight of the study is to assess whether is cultural identity and characteristic is still present against the rapid development within the surrounding area.

Townscape characteristic study seeks to show the important role of townscape which reflects the relationships between the elements a city has when composed with the urban fabric and the sense of place and identity it beholds which determined the success of a city. This highlights the importance of townscape towards a better living where the concept of townscape must be implemented when designing a city in order to make sure a strong character and identity can contribute towards a lively sense of place in which may affect every turn of activities for the people that live in it while carrying out their lives within the city. This concludes the importance of having good townscape as it affects the people living within the city.

\section{THE HISTORIC PETALING STREET: KUALA LUMPUR'S CHINA TOWN}

The China Town of Kuala Lumpur begins within the year 1850, during the establishments of a small base on the confluence of the Klang and Gombak River. This is due to the purpose of finding tins from the explorers. After tin being found within this area, a settlement flourished which was known as a muddy estuary or what the locals would call Kuala Lumpur. Chinese workers from the southern area of China came down to the area in order to work as tin miners resulting in thousands of people. Fights among the workers themselves and with the Malay rulers claiming rights for the tin mining causes wars which resulting to a decade of civil war from the year 1866 later with the international interests from the British help in keeping the city alive and marks the history of Kuala Lumpur.

The year 1875 marks the beginning of the British colonial rule within the country when a British resident was appointed in advising the Malay Sultans. Kuala Lumpur grown and was named as the capital city of Malaya further with the British government's buildings were built in 1880. However, in 1881, a major fire had destroyed the area, thus causing the British to rebuild the town using tiles and bricks into what we see as the China Town stood today. This marks the efforts for the urbanisation of the area from time to time.

Kuala Lumpur was then prospered as the high price of tin and rubber rises. The city became a service centre and began to expand with banks, hotels, restaurants were established in order to cater miners and planters, which causes the area to flourish. New buildings were built with a beautiful mix of European and Chinese designs. This concludes the area to have a strong sense of its past as many of the buildings still exist up until this day. 


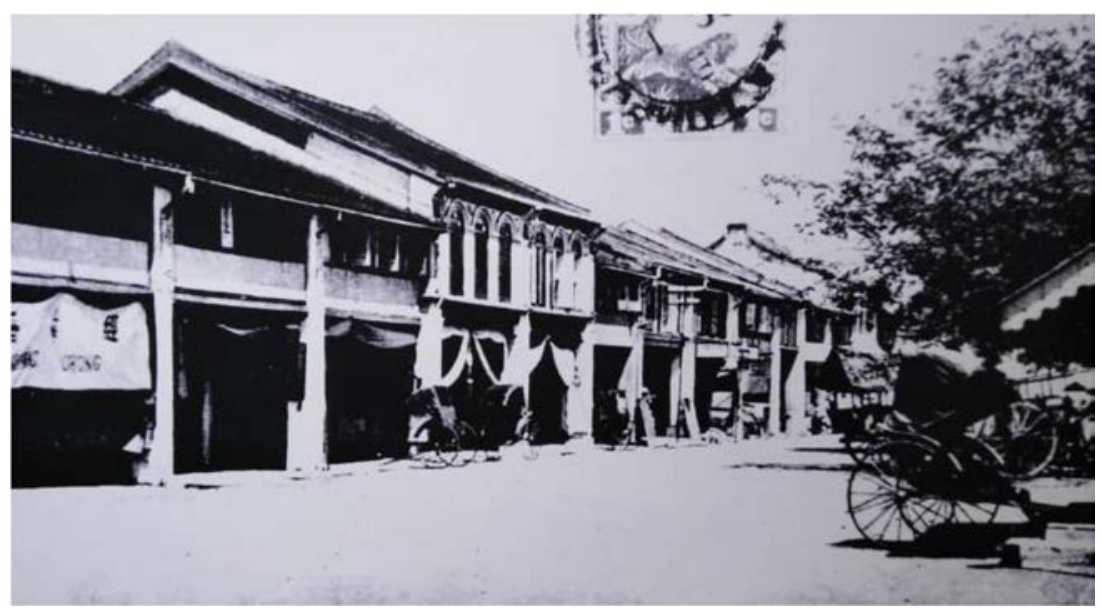

Figure 1: The first street shop houses built in Market-Square owned and occupied by Yap Ah Loy and family. (Source: Kuala Lumpur Gallery.)

Elements found within the China town area include Feng Shui, $5 \mathrm{ft}$ ways, and the shophouses built within the area. British established a law in 1885 where shophouses were built with an exact $5 \mathrm{ft}$ from the road allowing enough space for a covered walkway protecting pedestrians from rain and shine. These sidewalks often seen nowadays to be much lower than the main road due to the sewer and other utilities were buried beneath the streets as the city grew older. In certain areas, the older the shophouses, the lower the sidewalks are.

As the name itself suggests, the shophouses is both a shop and a house for its occupants. This concept was brought all the way from southern China by the immigrants who came to Malaya and can be seen in many other urban centres of Malaya. In Kuala Lumpur, the shophouses can be considered as a dominant type of building within the city. The idea is the merchant can live and work in the same building and were popular throughout World War II. The plan of the buildings was long and narrow connected by walkways and was stacked within a grid of shophouses (Fig. 1). Each shophouses place the kitchen at the rear end of the plan, a central area exposed to the sunlight that acts as an air-well that separates the kitchen and the shops at the front of the building. The upper plan of the building places the house for the merchant. The façade of the shophouses differs with its own style and identity according to the year it was built. This shows the strong identity it beholds and carries to the place and to the history of the area.

\section{TOWNSCAPE ASSESSMENT AND ANALYSIS}

For this study, a townscape assessment is carried out to evaluate the condition of the townscape with selected variables. Townscape evaluation is a quantitative data collection methodology used to assess the physical condition of the urban heritage areas. This method involves a scoring system and has been used to assess the effectiveness of Townscape Heritage Initiatives schemes in the UK [11]. Improvements in sociocultural indicators in the score sheet have been made and used in the assessment of historic urban characteristics of the study area. Although sociocultural characteristic is an intangible element, for this study, sociocultural characteristics are assessed based on the physical evidence of the condition of the architectural heritage present. 
A visual townscape evaluation was carried out to identify the changes in the selected area. The variables used thematically cover on three aspects which are on the environmental quality, special characteristics and identity, and thirdly include the appreciation on the heritage view from the observer. The evaluation covers the townscape characteristics adding the indication on heritage view in capturing the impacts of urbanisation done towards the area. The characteristics of each variable are scored based on the ranks of 5 being the highest score and to 0 being the lowest score. This scoring system works through the Likert's style scale only it ranges from "worst" to "excellent" with 0 as the "absent" element. The total of the scoring would be of a sum of 125 scores (Table 1).

Table 1: Division of scores for each theme.

Themes

$\begin{array}{lcc}\text { Streetscape \& Environmental Quality } & 75 & 60 \\ \text { Special Characteristic \& Identity } & 25 & 20 \\ \text { Heritage in View (Appreciation) } & 25 & 20 \\ \text { TOTAL } & 125 & 100\end{array}$

Part A: Streetscape and Environmental Quality consist of the study on the physical characteristics of the study area, which includes the streetscape and environmental quality of the area. The fifteen variables for this theme are on the physical appearance of the place in term of the condition of the pedestrian area, street scene, cleanliness, state of buildings, edge feature quality, floor scape quality, legibility, sense of threat, traffic, planting, vitality, resting area, signage, street furniture quality and appropriateness of traffic flow. This visual survey is solely by the researcher's point of view on the selected point within the China Town area. It covers the major percentage within the survey, as it contributes $60 \%$ on the percentages of the scoring system. This theme denotes the sociocultural characteristic of the place. Usage of spaces and cultural activities carried out in the areas affected the score obtained for all the assessed variables. Higher scores are usually obtained in a vibrant space where most of daily activities took lace, where lower at transit area between heritage street and new development.

Meanwhile, Part B focuses on the special characteristics and identity of the place. It covers the attentiveness of the authority of the importance of the cultural built heritage of the place and its role as a heritage area. The variables assessed for this theme are the evidence of conserved elements, historic reference seen, nomenclature/place reference, quality of new development in the context of heritage reference and the harmony between new and old buildings. For this part, the variables are assessed on the representation of heritage appreciation and the sustainability of cultural activities for the area with the introduction of urbanisation within the historic area. Integrity of building and spaces, changing of activities to accommodate modern demand is scored to establish the level of interruption to the townscape elements. All these are represented by the quality of conservation approach and heritage management by the stakeholders. This theme represents $20 \%$ of the overall score.

The final part of the assessment is the appreciation of heritage in view. Assessment for this theme is based on the observation on five variables that are the structural building condition, heritage resource available, building usage, façade quality and the appropriateness of conservation work. This theme also represents twenty per cent of the overall score. 
Variables assessed are on the character of the old shophouses and how it has been conserved. The higher score denotes good conservation work carried out to retain its cultural activities and the lower score represent the opposite.

\subsection{Analysis of the townscape evaluation}

The surveys on the townscape evaluation were conducted within the China Town area of Kuala Lumpur. The scoring is based on a total of 12 points of view within the important nodes and edges of China Town, Kuala Lumpur. The observation process is done based on point to point method where the researcher moves along the streets towards the next observation point. All the assessment carried out on the observation points are marked down together with photographic evidence for further research. After all the assessment are carried out throughout all the observation points, the scoring of each assessment is summed up and marked on the map in order to create an overall analysis as a reference. Fig. 2 shows the observation point of the townscape evaluation of China Town, Kuala Lumpur covered within this research.

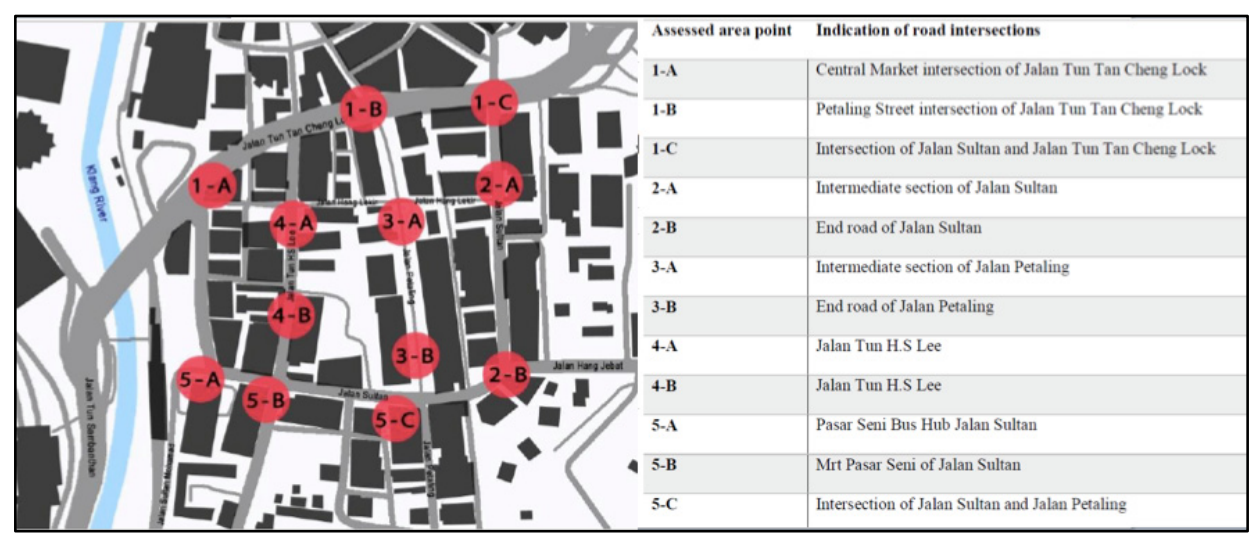

Figure 2: Assessment points at Kuala Lumpur China Town.

The townscape evaluation assessment carried out provides a numerical result, thus allowing the data to be shown in a graph plotted according to the point location assessed showing the scoring of the performance on the area. This allows the data to be analysed whether the point assessed are of a weak or excellent performance based on the three themes for further studies.

\section{RESULTS AND DISCUSSION}

Based on the data from the townscape assessment that had been carried out within this research, the physical quality of the area is assessed. All the quantitative values achieved based on the scores obtained from the assessment are plotted on the graph (Fig. 3).

The highest scores obtained can be seen along the main road of the assessed area. These areas include the main road at Jalan Tun Tan Cheng Lock (Fig. 4), Jalan Tun H.S Lee and Jalan Sultan. As Lynch proposed that the street is a path that is enlivened by a series of nodes that meets paths, thus causing activities to intensify, which reflects the place with functions and movements [12]. A continuous activity was met along with different nodes which allows the area to be vital, thus allowing the area to have a better score. 


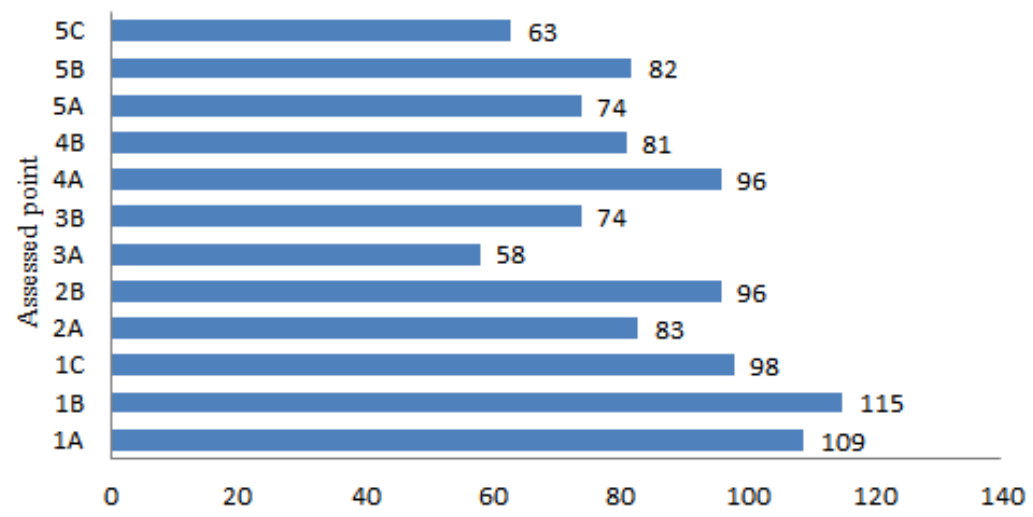

- Overall scores (125)

Figure 3: Overall scores for assessed areas.
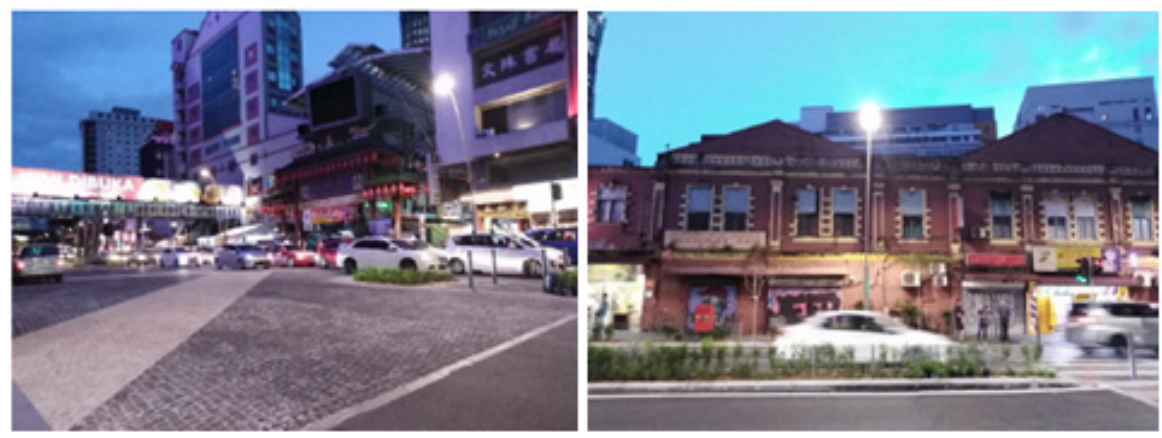

Figure 4: Jalan Tun Tan Cheng Lock (1A and 1B) obtained the highest score because of the good townscape quality.

As the main road for the vehicular users who passes the area from Pasar Seni to Puduraya, Jalan Tun Tan Cheng Lock is prominent and has the heaviest traffic flow compared to other main roads as such Jalan Tun H.S Lee and Jalan Sultan. This road connects the area to Kuala Lumpur city area hence making the area as vital and full of activities. This area had strong identity values due to its location near Central Market and Kasturi walk. Central Market had stood within the area built since 1937 and survives in becoming successful adaptive reuse of historical buildings. The higher score indicates the importance of the building with its sense of place and a strong identity with its place and its pasts has been retained. Improvements were seen to be made along this area within all the three themes stated on the assessment hence allowing the area to have much higher scores. The entrance to Petaling Street is also designed to represent the characteristic of Chinese architecture (Fig. 5). This is a part of urban improvement and regeneration scheme of carried out by the local authority to enhance the identity of heritage areas in Kuala Lumpur. 

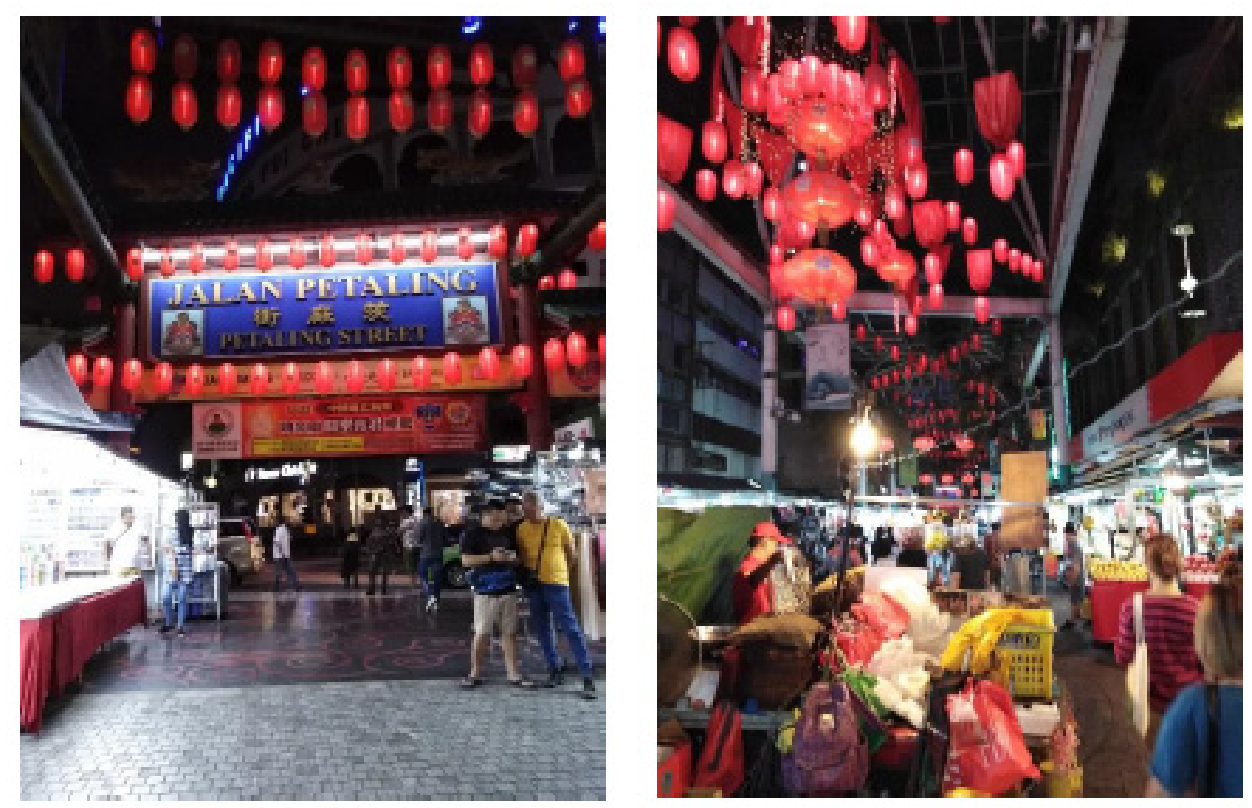

Figure 5: Entrance of Petaling Street welcomes tourists with lantern and gateway representing China Town.

The lowest scores obtained on the assessed point of location are on point 3-A and 5-C, respectively. With the scores of only $46.4 \%$ and $50.4 \%$ respectively, the areas are marked as one the lowest assessment scores for this study. Point 3-A is located along Petaling Street and gained scores of only $34.7 \%$ for Part $\mathrm{A}$ and $60 \%$ and $68 \%$ on part $\mathrm{B}$ and $\mathrm{C}$ respectively (Fig. 6). This is due to the presence of small alleyways from the results of vendors along Petaling Street allowing it to be only for the pedestrian users hence resulting in the zero scores of the street furniture quality, appropriate resting place factors and planting area provided at the area and personal safety from traffic at the area. However, the scores obtained for part B and $\mathrm{C}$ are fairly good since there are the prominent place of reference at this area and the identity of the area reflects the sense of place along the street.

In addition, there is no harmony between the old and new development within the area and the building usage within the area are low from the observer point of view. The low score obtained because most of the economic activities are carried out along the street by the vendors compared to businesses in the new shophouses unit. Although the on-street trading that spread out along Jalan Petaling create a vibrant ambience, the low number of people within this area affected the marks and leave a huge difference between the score. Furthermore, the insensitive new built has not consider complementing architectural heritage of the neighbouring area has created imbalance in townscape view. Ironically, this area is located opposite the main entrance of China Town (Fig. 5). The imbalance approach to development within the same area within the city centre is questionable. A good urban design approach should consider significance of the place and provide a balance design to ensure the sustainability of the cultural identity of the place. 

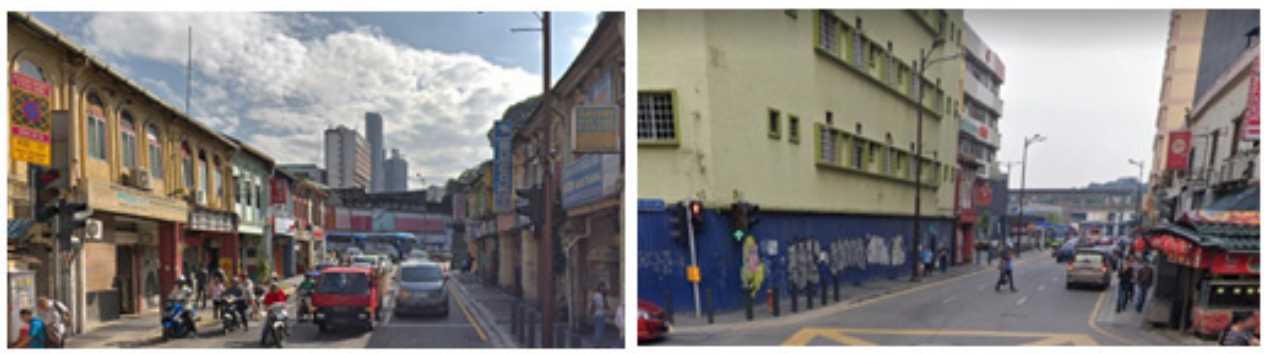

Figure 6: View towards Jalan Sultan (3-A and 5-C) with the lowest score, reflecting the poor quality of townscape where monotonous new development has not considered complementing the architectural characteristic.

Jalan Tun H.S Lee is where the two important architectural heritage buildings: the Sri Mahamariamman Temple and Guan Di Temple. Both of these worship houses had attracted visitors to visits the area. Guan Di Temple is a Taoist temple which represents vibrant colours on its surrounding. This has attracted many tourists to come and visits the area. Although located within the Chinese area, the Sri Mahamariamman Temple is said to be the oldest Hindu temple in Kuala Lumpur in which had been standing ever since the year 1873. The temple had been indicated as an important cultural and national heritage as it was an important place of worship for the early Indian immigrant back in the day.

These buildings set the important architectural landmark for China Town area as it acts as a point of reference mostly in the external form. It also represents the sociocultural identity of the residents. The Sri Mahamariamman temple stood strongly with a different visual street elevation between the rows of shophouses that singles out its character that differ from the building surrounding it. This assessed point (4-A and 4-B) scored a high, above 80 scores for the cultural identity preserved and pleasant townscape characteristic that still intact within the urbanised city area.

Other important factors that contribute to a good score for the townscape evaluation found within the studied area are the legibility of the surroundings. Based on the observations, the areas within the main roads have a clear image of the town. This allows the observer to move about easily and quickly. A distinctive and legible environment is important as it offers security and at the same time, heightens the intensity of the human experience. Signboards, route signs, street road names are one of the way-finding devices that helps people to move around and not to get lost within the area. The correct placements of these items are important as it helps people to navigate easily within the city. Moreover, the placement of signboard with historical explanations can promote the culture that our city has and can offer to the tourists that visit the area.

\section{CONCLUSION AND DISCUSSION}

Throughout identifying all the factors that contribute the impacts of urbanisations, it is identified that urbanisations give out positive and negative impact throughout the physical characteristics of a town represented by the activity patterns and the identity it beholds. Located at the heart of the city centre and as part of the urban growth, China Town Kuala Lumpur can never run from the urbanisations that help in emerging for economic growth towards a city. People from urban areas move to cities due to many factors which are deemed convenient with all the facilities it offers together with job opportunities and increasing living standards as a living human. 
The introduction of new urban initiatives in moving towards Kuala Lumpur City Plan 2040 [13], China Town should represent both the past and the future of the city. Modernisation should not and could not be stopped as it represents the growing process for city. A city is to sustain by adapting to the new use without compromising its heritage values and identities. A sensitive development plan should help in sustaining the special ambience. With massive developments moreover as a capital city for Malaysia, a modern developing area can help in regenerating the economic activities within an area. The increasing number of the population helped in increasing the buying and selling process; thus boosts up the economy of a city. Furthermore, this will enhance social interaction between the people who live, occupy or just passing area of the space in between buildings.

Jalan Petaling started as a business hub for Chinese traders and residents, today is one of the major tourist attraction in Kuala Lumpur. It is where tourists shop for souvenirs and promotes photographic attractions, which unconsciously helped in promoting tourism for the city. This place continues to serve as economic generating area from tourism and trading activities. Old shophouses within the area plays bigger role as an evidence of architectural heritage from the past of once a famous trading area.

However, the negative impacts of urbanisations can also be seen within the study area. Urbanisations lead to the developments of new projects that has affected to the growth in the number of foreign residents within the city centre. The foreign construction workers be it legal or illegal often live and work at the construction areas and hostels provided nearest to the work area. Most of the old shophouses offered the upper floors and cheap hotels and motels for these workers. It is a form of gentrification that occurred in many heritage areas. As unpleasant as it is to pinpoint the problems, this has cause the loss of cultural identity of the area. The reduced amount of the number of locals who visited the area is noticeable, which may cause the whole street of Petaling Street in China Town Kuala Lumpur to be seen as a Bangladesh or Nepalese street. This somehow poses a sense of threat the identity of the place.

On the other hand, Petaling Street is known for a place to bargain hunt cheap and pirated goods. This identity tarnished the once famous trading street, nonetheless, the pirated goods attracted many tourist. On the other hands, although new urban revitalisation projects such as mural arts were introduced to enhance back lanes and alleyways, an increase on the amount of vandalism still occurs. However, this has not created a major disadvantage for the area in terms of tourism. Besides that, unused buildings needed to be taken care of and propose adaptive reuse of the buildings to attract more activity patterns, thus increase socio-economic growth in the city. Many of the shophouses were adapted into boutique hotels and hipster café to attract locals and tourists. Letting new use and adaptation for the dilapidated buildings are a way forward to sustain this area and promotes regeneration initiatives. Nonetheless, a stronger conservation action plan is to ensure the sustainability cultural identity and the townscape characters that tell the story of the area. Moreover, locals stakeholders should be exposed more on the importance in managing heritage area to ensure that the historic fabric of town does not slip through the layers of urbanisations.

\section{ACKNOWLEDGEMENTS}

This research is part of a research entitled "Developing a Space Syntax Embedded Environmental Design Model (EDM) for a Safe Heritage Area" sponsored by the Ministry of Higher Education for FRGS/1/2017/WAB03/UITM/02/4 in which townscape assessment is part of the study. The author also would like to thank Universiti Teknologi MARA for facilitating the research. 


\section{REFERENCES}

[1] Deghati Najd, M., Ismail, N.A., Mohd Yunos, M.Y. \& Maulan, S., Historic urban areas in heritage tourism: Kuala Lumpur historic city centre, a potential asset. Applied Mechanics and Materials, 747, pp. 93-96, 2015.

[2] Shamsuddin, S., \& Ujang, N., Making places: The role of attachment in creating the sense of place for traditional streets in Malaysia. Habitat International, 32(3), pp. 399409, 2008.

[3] Kuala Lumpur Structure Plan 2020, Kuala Lumpur City Council.

[4] Samadi, Z. \& Yunus, R.M., Urban heritage streets' revitalizing attributes. Asian Journal of Environment-Behaviour Studies, 3(7), pp. 69-78, 2012.

[5] Ismail, W.H.W., Contemporary uses of buildings on a heritage street. Procedia Social and Behavioural Sciences, 170, pp. 633-641, 2015.

[6] Lynch, K., What Time Is This Place? MIT Press, 1972.

[7] Askari, A.H. \& Soltani, S., Contribution of building façades to attractive streetscapes: Study of two main streets in Kuala Lumpur City. Journal of Design and Built Environment, 18(1), pp. 29-40, 2018.

[8] Tuan, Y.F., Topophilia: A Study of Environmental Perception, Attitudes, and Values, Columbia University Press: Englewood Cliffs, 1990.

[9] Boussaa, D., Urban Regeneration and the Search for Identity in Historic Cities. Sustainability. Sustainability, 10(1), p. 48, 2018.

[10] Ja'afar, N.H., Sulaiman, A.B., \& Shamsuddin, S., Traditional street activities in Kuala Lumpur city centre. International Journal of Multidisciplinary Thoughts, 2(1), pp. 93105, 2012.

[11] Said, S.Y., Syed Zubir, S.S. \& Rahmat, M.N., Measuring physical changes in an urban regeneration scheme. WIT Transactions on Ecology and the Environment, 191, 11651174, 2014.

[12] Lynch, K., The Image of the City, MIT Press: Cambridge, MA, 1960.

[13] Draft Kuala Lumpur Structure Plan 2040, PSKL2040. www.dbkl.gov.my/klmycity2040/. Kuala Lumpur CIty Council. Accessed on: Jun. 2020 . 